\title{
Online Consumer Trust: Trends in Research
}

\author{
Antonina Bauman ${ }^{1^{*}}$ and Reinhard Bachmann ${ }^{2}$
}

\begin{abstract}
This paper presents the literature review of studies published in 2004-2014 (Web 2.0 period) in the area of consumer online trust. Based on the content analysis of 138 papers, this study highlights three major research themes: (1) trust models, (2) technological, and (3) social factors impacting online trust. It also explores topics in each major theme found in direct studies of online consumer trust. Since this literature review uses the concept-centric approach, it points out not only the major trends in research but also three understudied areas: (1) green trust, (2) trust recovery, and (3) the role of ethics in developing online trust.
\end{abstract}

Keywords: online trust; research trends; literature review

Submitted: May $20^{\text {th }} 2017$ / Approved: July $3^{\text {rd }} 2017$

\section{Introduction}

The Internet has become an indispensable tool for international business as it does not recognize physical borders between countries and gives buyers access to online sellers from all continents. Being so far and yet so close, how does one know if a seller is genuine? With the ease of creating a commercial website and relatively affordable cost, the number of online stores has skyrocketed. Don Davis (2012), the editor of Internet Retailer magazine, estimated that 25 million online retailers sell products over the Internet. Each retailer tries to attract customers and entice them to complete a purchase. How does one know which online retailer (e-retailer) to trust and which e-retailer not to trust? The answer to this question is essential to academic researchers, businesses, and customers. Academic researchers create and extend knowledge of online trust; businesses apply that knowledge to practice to develop long-term relationships with customers, while customers become informed online shoppers.

Despite the extensive research in the area of e-commerce, the studies of online consumer behavior with emphasis on developing online trust are not that numerous and systematic. Chang, Cheung, and Lai (2005) in their literature review analyzed factors impacting the adoption of online shopping and noted that although trust has a significant impact on e-commerce, it has not been sufficiently studied and requires further investigation. Thus, the objective of this paper is to identify both common themes in online trust research conducted over a decade of the Web 2.0 environment (2004-2014) and gaps that could suggest directions for future exploration of this area. The purpose is not to offer a comprehensive review of the vast body of research but rather investigate what aspects of online trust need more exploration.

This paper is structured as follows: it starts with an overview of online trust that creates a foundation for and leads to the presentation of main trends in online trust research; then follows the explanation of how the search of publications for the literature review was conducted. After that, we present the result of the search along with the different types of article classification. Next section discusses results while Section 6 describes the contribution and practical implications. Finally, Section 7 concludes the literature review by listing limitations and offering suggestions for future research.

\section{Defining Online Trust}

Before discussing the literature on online trust, it is necessary to define the phenomenon itself and investigate how online trust differs from traditional trust. While numerous interpretations of the concept of trust exist (Fukuyama, 1995; Mayer et al., 1995; Mollering, 2006; Pettit, 1995), they all focus on the following elements that have to be present for trust to occur (Bachmann, 2010; Barber, 1983; Cook et al., 2009; Dietz, 2011; Grabner-Kraeuter \& Kaluscha, 2008; Rousseau et al., 1998):

- Two actors - trustor and trustee - must exist to develop trust

- Vulnerability must be present (trust exists only in a risky or uncertain situation)

- $\quad$ Trust is a context-sensitive concept (trust is affected by many subjective individual and environmental circumstances, and as such, is dependent on the context of the situation)

While shopping online, a consumer, as a trustor, finds himself/herself in a risky situation where he/she uses the Internet as a tool to communicate his/her needs to an e-vendor and submits private information about himself/herself. He or she chooses a method of payment and expects the website to be a reliable means for the transaction and the vendor to behave in an honest and professional manner when fulfilling the purchase request.

A definition of online trust was formed as "an attitude of confident expectation in an online situation of risk that one's vulnerabilities will not be exploited" (Beldad, de Jong, \& Steehouder, 2010, p.860) and reflects consensus among online trust researchers that the nature of,

(1) School of Business, Emporia State University, USA

(2) SOAS, University of London, UK

*Corresponding author: abauman@emporia.edu 
and basic meaning of, online trust is not fundamentally different from the concept of face-to-face trust (Shankar, Urban, \& Sultan, 2002; Jarvenpaa \& Rao, 2003; Corritore, Kracher, \&Wiedenbeck, 2003; Wang \& Emurian, 2005), notwithstanding that a human being has to trust an object created by a human being rather than another human being (Corritore et al., 2003).

Online trust has been identified as a critical component of a business strategy as it reduces perceived risk and creates positive wordof-mouth which, consequently, impacts a customer's decision to buy (Chen \& Barnes, 2007; Fan, Ming, \& Whinston, 2005; Fang, Chiu, \& Wang, 2011; Hassanein \& Head, 2007). Consumer trust and satisfaction with the transaction form the foundation for the long-term commercial relationship between a company and a customer (Kim, Ferrin, \& Rao, 2009; Morgan \& Hunt, 1994).

\section{Literature Search}

With the growing popularity of e-commerce, the number of academic studies in that area increased significantly covering various aspects of online retailing. The scope of research widens from technical issues of the business platforms to long-term customer relationships. However, publications aimed at the review of the previously conducted research are rare and rudimentary. Wareham, Zheng, and Straub (2005) offered a discussion of the critical themes in e-commerce focusing on publications in the IS (Information Systems) journals during the timeframe of 1997 - 2003. Wang and Chen (2010) reviewed studies published in the first decade of online commercial activities (19992008) and noted that the focus of research in electronic commerce shifted from technology orientation to management.

As the technology matured, the focus of studies has naturally moved to managing electronic commerce activities that could attract and retain consumers. At the same time, marketing efforts have more and more been aimed at establishing customer relationships based on trust and commitment (Morgan \& Hunt, 1994). While this shift in research is acknowledged, there seems to be a lack of observations and understanding of trends in trust research in the online commercial environment. The latter is what this paper will provide.

The period for this literature review was selected as 2004-2014 because 2004 is noted to be a pivotal year for the Internet commercial development. During that year, the term 'Web 2.0' was introduced to e-commerce to describe Internet technological abilities that drastically changed the business model. O'Reilly (2007) summarized the breakthrough in technology that allowed building computer applications directly on the Web rather than on desktops. This achievement resulted in the consumers' ability to create content in the form of text, pictures, or videos that would deliver value to other people and businesses. On the one hand, it became relatively easy for individuals to open an online store, but on the other hand, it made individuals more powerful regarding creating or ruining a company's reputation by posting reviews online. Web 2.0 developments lead to fundamental changes in business models based on social networking, interaction orientation, personalization/customization, and user added value
(Wirtz, Schilke, \& Ullrich, 2010). The year 2004 was noted by Clarke and Pucihar (2013) as the beginning of the social network services era in the digital economy.

The period of 2004-2014 is also important in research of online trust as it marks the end of the Web 2.0 period and the beginning of the Web 3.0 (Nations, 2016). Although the term Web 3.0 was coined by John Markoff (2006) in 2006, the transition to the Semantic Web did not happen then as it took time to combine artificial intelligence and mobile Internet devices. Thus, this literature review covers the decade of online trust research in the Web 2.0 environment as it looks into the issue of trust between customers and e-vendors. The process of selecting articles for this review followed recommendations expressed by Okoli and Schabram (2010) and Rousseau, Manning, and Denyer (2008).

The literature search was performed within two databases: the Web of Science and EBSCO Host. According to Thomson Reuters (Site 1), the Web of Science (formerly Web of Knowledge) database was the first online citation resource. It currently has 30 years of bibliometric experience, maintains over 90 million records with over one billion cited references. The Web of Science provides access to 3,000 journals in over 55 social science disciplines and 250 scientific journals, thus meeting the goal of this paper. IEEE Xplore Digital Library of the Institute of Electrical and Electronics Engineers (Site 2) maintains the database of over 100 peer-reviewed journals, lists almost 2 million full-time documents and 4 million records. Another popular database - ACM - the Association for Computing Machinery - digital library (Site 3) provides 407,367 full-text articles which cover the fields of computing and information technology. Since online trust is studied by marketing, management, psychology, and other social sciences along with computer science and information technology, the Web of Science database was selected as the most appropriate for the purpose of this study.

The search was performed using the following two key phrases: "online trust" and "e-commerce" in the "Topic" category of records from 2004 to 2014 inclusively. These phrases have been carefully selected to avoid the problem of using trust related specific terms or "buzzwords" that "appear and disappear from literature" (Levy \& Ellis, 2006, p. 190). The "Topic" rather than "Text" category was selected to narrow down the search results only to the articles focusing on studying trust directly rather than other aspects of e-commerce that might only indirectly involve online consumer trust. The other selection criterion was that papers should be full papers publications in peer-reviewed English language journals. With this search approach, the Web of Science database returned 123 results.

The second database used for this study is EBSCOHost, a fee-based online research service with 375 full-text databases and a collection of 380,000-plus e-books (Brynko, 2013). The search based on the same combination of "online trust" AND "e-commerce" returned 28 results. Papers found in EBSCO were combined with the papers found through the Web of Science. As there were 14 duplicate articles - those found in both databases, the total number of papers under review was 138 . 
Initially, a "practical screen" (Okoli \& Schabram, 2010, p.7) was conducted to determine which studies should be selected. At that time abstracts of the papers were reviewed to ensure that articles indeed cover the subject of online trust. The data about publications were entered in an Excel worksheet which made filtering of records easier. In the second round of review, each full article was read, and the content coding and classification of the articles were completed. Based on the named selection criteria, some publications were excluded from the review:

- Among the search results, there was one book and individual chapters in three books discussing online trust in e-commerce or $\mathrm{m}$-commerce. Since the focus of this review is on the article publications in academic journals, these four publications were not considered in our subsequent analysis.

- One result was a publication in Spanish, although its abstract was in English. Since the full paper was not available in English, it was not included in further analyses.

- Conference papers or conference abstracts rather than full papers published in the conference proceedings were not considered. Clarke and Pucihar (2013) have already reviewed 1,000 conference papers submitted to the Bled eConference in 25 years (1988-2013) and there was no need to duplicate the previous study. Fifty-five conference presentations were dropped from our list.

- Articles studying trust in non-commercial websites (non-profit and government organizations) were rejected for further analyses as not meeting our selection criteria.

- Articles researching auctions or consumer-to-consumer transactions were not taken further as consumer bidding behavior is different from the consumer buying behavior in a traditional retail environment.

- Doctoral dissertations, master's theses, and unpublished working papers were excluded from our analyses.

As a result, fifty-four full papers out of 138 publications in the area of online trust have been included for the analysis of trends in online trust research. Although this search is not exhaustive, it captures a sufficient number of publications in this field.

\section{Classifications of Publications}

First, all fifty-four publications were classified based on the type of the article: literature review, theoretical paper, or empirical research. For the purpose of this paper, literature review articles were identified as those presenting work of others over a specified period or covering a specific topic. Such articles "summarize existence evidence, identify gaps in research and provide a framework for positioning research endeavors" (Okoli \& Schabram, 2010, p. 3). Theoretical papers were defined as papers presenting a theoretical analysis based on ideas not supported by empirical evidence. Empirical research papers were classified as such if they reported results of the primary research. Table 1 below shows the results of this grouping.
Table 1. Classification of publications based on the type of the article.

\begin{tabular}{|l|c|c|}
\hline Type of the article & Number of publications & Percent of the total \\
\hline Literature review & 5 & $9.25 \%$ \\
\hline Theoretical paper & 6 & $11.11 \%$ \\
\hline Empirical research & 43 & $79.63 \%$ \\
\hline Total & 54 & $100.00 \%$ \\
\hline
\end{tabular}

Four out of five studies classified as literature reviews were topic-specific surveys of literature where the author(s) selected an aspect of online trust research, and then found, and analyzed academic studies exploring that topic. For example, the topic of web design was investigated by Cyr (2014) and Karimov, Brengman, and van Hove (2011), adoption of e-commerce Chang et al. (2005), and antecedents of online trust were reviewed by Beldad, de Jong, and Steehouder (2010). One study (Urban, Amyx, \& Lorenson, 2009) reported the state of research in the area of online trust from a holistic perspective and showed different aspects of online trust research - a process of developing online trust, online privacy and security, website design, and heterogeneity of trust.

As the literature review studies on web design show, there is empirical evidence that a website has cues which impact developing consumer online trust, satisfaction, and loyalty but there is no consensus among the researchers on exactly what online features signal trustworthiness to online shoppers (Cyr, 2014). Thus, Cyr (2014) suggested three categories of website key elements - navigation, information, and visual, while Karimov et al. (2011) discussed visual design (graphics and structure), social cue design (social media, online help and humanlike features), and content design (product and company information, and assurance of transactions). Both reviews on the website design noted the abundance of factors influencing consumer perceptions of online trustworthiness.

Chang et al. (2005) reviewed 45 papers that they found relevant to their study and identified three main categories of research on what impacts e-commerce acceptance - perceived ability of a website to complete a transaction, characteristics of a customer, and perceived characteristics of a product. Meanwhile, Beldad et al. (2010) reviewed literature related to studying antecedents of online trust based on three groups: consumer-based, website-based, and company-based determinants of trust. These two studies support each other as areas of research identified by Chang et al. (2005) correspond to categories of determinants of trust introduced by Beldad et al. (2010).

Six theoretical papers covered three major areas: the concept of online trust, legal, and technological factors impacting online trust. Theoretical foundations of online trust were presented by papers published by Riegelsberger, Sasse, and McCarthy (2005) and Wang and Emurian (2005). O'Hara (2005) discussed how contract statutes and court doctrines could be modified in order to enhance consumer trust while M. R. Muhammad and M. Muhammad (2013) reviewed Shariah laws and how online trust model fits those. The impact of cooperative review mechanisms and the adverse effect of trust certifications were 
conceptualized respectively by Fan et al. (2005) and Edelman (2011). The overall ambition of the theoretical papers was to offer different pieces to a big overall picture of the online trust concept.

The forty-three articles reporting results of empirical studies were analyzed with the purpose of identifying the major trends in online trust research. Figure 1 illustrates these trends. An interesting observation is that all of those studies are conducted with quantitative research methods. A few researchers used focus groups to discuss the items on the survey before collecting the data, but no qualitative studies in the area of online trust research in the commercial environment were found in the articles selected for the review. The following section presents the subject areas of these forty-three studies.

\section{Main Areas of Online Trust Research}

Following the established process for conducting a literature review, data extraction had to be completed before the analysis and synthesis of studies could begin (Okoli \& Schabram, 2010). The review of the content of forty-three empirical studies was performed to determine both clusters and outliers of research areas by common data extraction procedures (Rousseau et al., 2008). As the purpose of the literature review was to establish research trends in the area of online trust in the commercial environment, information about the main study area was extracted from each article. Thus, the review process was completed in several steps: (1) reviewing citations and abstracts followed by (2) the review of the full text of articles to complete a "thematic analysis" of areas of study (Tranfield, Denyer, \& Smart, 2003, p. 218). During the third step, the content of each paper was coded with a keyword that reflected the main research area and later analyzed (step four). This method has been defined as an interpretive approach which was validated by researchers previously (Rousseau et al., 2008; Tranfield et al., 2003).

Following Tranfield et al. (2003), a data extraction form was used in preparation for the content analysis. The form was an Excel worksheet which contained details of the information source (authors, title, publication, year of publication) and the context of the study. After the review of the full text of each article, all articles were coded based on the main study area and the research method. The use of the Excel worksheet allowed for easier filtering of data based on selected criteria - author, title, publication, year of publication, main study area, research method, and a study sample size. The form served as evidence of papers which went through the review, a visual representation of the link between the articles and the aim of the literature review, and data storage (Tranfield et al., 2003).

The "bottom-up" approach was used during the coding process when papers were divided into groups according to research topics covered in studies. This process of grouping is a commonly used and validated approach in qualitative data analysis consisting of identifying concept categories incrementally during the coding process rather than using a predetermined list of concepts (Carley, 1993; Gray \& Densten, 1998). This method helps to discover new trends rather than trying to fit current research into the list of existing categories.
Once the agreement between two researchers had been achieved, the review of codes resulted in the following grouping: three major research categories and twelve subcategories. Three main categories of topics were identified as trust models, technological factors, and social factors impacting online consumer trust. Within each category, specific sub-categories were grouped. The graph in Figure 1 follows the approach which was originally undertaken by Ngai and Wat (2002) to present the topic classification.

The three research categories shown in Figure 1 are suggested based on the following theoretical concepts:

(1) A trust model offers a holistic (overall) picture of online trust development showing antecedents of online trust under a specific context. Since online trust is highly contextualized, these models provide a theoretical foundation to better understand the online trust phenomenon

(2) Technological factors reflect a cognitive approach to trust as they show a company's ability to complete a transaction in a secure environment which is rationally evaluated by consumers. These factors also correspond to the concept of institutional trust where an individual treats an institutional structure and institutional arrangements as ways to reduce risk in a particular situation (Bachmann \& Inkpen, 2011).

(3) Social factors correspond to the affective approach to trust as these factors describe consumer's perceptions and emotions about perceived trustworthiness of a website.

Figure1. Main categories of online trust research

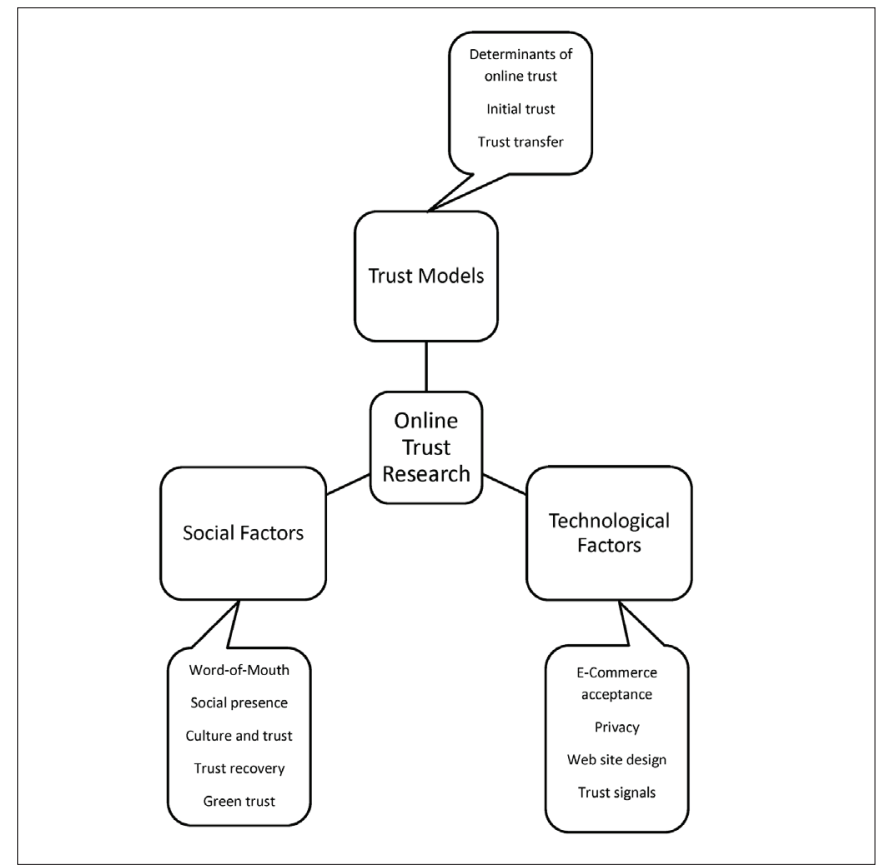


Table 2 shows the frequency of article distribution by subject subcategories of research. Each key category is looked into in greater depth below.

Table 2. Distribution of articles by the topic of research.

\begin{tabular}{|l|r|r|}
\hline Topics of research & Number of articles & \multicolumn{1}{l|}{ \% of total } \\
\hline Determinants of trust & 14 & $32.56 \%$ \\
\hline Website design & 5 & $11.63 \%$ \\
\hline Trust signals & 5 & $11.63 \%$ \\
\hline Initial trust & 4 & $9.30 \%$ \\
\hline E-commerce acceptance & 3 & $6.97 \%$ \\
\hline Trust transfer & 3 & $6.97 \%$ \\
\hline Privacy & 2 & $4.65 \%$ \\
\hline Social presence & 2 & $4.65 \%$ \\
\hline Word -of-mouth & 2 & $4.65 \%$ \\
\hline Culture and trust & 1 & $2.32 \%$ \\
\hline Green trust & 1 & $2.32 \%$ \\
\hline Trust recovery & 1 & $2.32 \%$ \\
\hline & 43 & $100.00 \%$ \\
\hline
\end{tabular}

${ }^{\star}$ Note: Due to rounding, the actual total is $99.97 \%$.

\subsection{Trust Models}

The largest group of articles on online trust in e-commerce (48.84\%) belongs to the category of trust models. This finding was not surprising as the phenomenon of online trust is relatively new and "requires a strong theoretical basis" (Benbasat, Gefen, \& Pavlou, p. 6). Papers found in this category focus on online trust as a process and look at what causes trust to occur, develop, and/or transfer from one environment to another.

- Determinants of online trust are factors that lead to developing online trust. Studies in this category focus on a variety of antecedents ranging from consumer personal characteristics and website features (Chang \& Fang, 2013), system structural assurance (Chau, Hu, Lee, \& Au, 2007) to country specific consumer cultural characteristics (Casaló, Flavián, \& Guinalíu, 2011; Eid, 2011).

- Initial trust as the first stage in online trust development was the focus of four papers under this review (Chen \& Barnes, 2007; Li, Jiang \& Wu, 2014; G. Wu, Hu, and Y. Wu, 2010; Yaobin \& Tao, 2007).

- Trust transfer as a concept of applying trust in a vendor in one domain (traditional, brick store) to another (online domain) was explored by Bock, Lee, Kuan, and Kim (2012), Kuan and Bock (2007), and Lee, Kang, and McKnight (2007).

\subsection{Technological Factors}

Articles included in the technological factors category investigated ecommerce adoption, privacy issues, website design, and trust signals.

- $\quad$ E-Commerce acceptance: In two articles found on this topic, acceptance of online shopping is viewed from the consumers' perspective rather than from the companies' side. The scope varied from ecommerce adoption by older generations of buyers (Chattaraman, Kwon, \& Gilbert, 2012) to a single country case of Tanzania (Makame, Kang, \& Park, 2014). The third paper (Roy \& Ghose, 2006) discussed the process of e-commerce adoption as a two-phase action: first Internet non-users are converted into Internet users, and then from the Internet users they transition to e-commerce buyers.

- Privacy issues: Despite the advances in technology and standardization of e-commerce business platforms, the issue of privacy remains one of the key research areas of online trust studies. The concept of privacy on the Internet is defined as people's ability "to control the terms under which their personal information is acquired and used" (Culnan, 200, p. 20). Personal information includes both private and public data. Companies that can collect consumer data to analyze customers' needs and spending habits have a strategic advantage in a competitive marketplace (Wheelen, Hunger, Hoffman, \& Bamford, 2015). Due to the technological developments that make collecting customer information online an easy task for marketers, the public portion of the personal information has been increasing (Caudill \& Murphy, 2000). Privacy concerns relate to data collection techniques as well as data storage, processing and handling (O'Brien \&Torres, 2012; Peštek, Resić, \& Nožica, 2004). To protect their privacy, consumers expect to have a certain degree of control over their information submitted online and have online tools that help to exercise that control.

- Website design: According to one of the basic principles of the trust-building process, a trustor's experience with the object of trust determines how much trust toward that object will be established (Blau, 1974; Luhmann, 1979). Since the object of online trust is a website, customers develop trust in a company according to their experience of dealing with the company's website. If consumers' perception of the website is that of a company capable of delivering promised value, then consumers are more likely to develop trust (Bart, Shankar, Sultan, \&Urban, 2005). This subcategory was in the top three most frequently studied topics in the articles selected for our analysis.

- Trust signals or trust marks are website elements which are "presented in an effort to dispel consumers' concerns about Internet security and privacy and, therefore, to increase firm-specific trust levels" (Aiken \& Boush, 2006, p. 310). Among trust signals studied by researchers are seals of approval from trusted third party (certification systems that promote trust online), photos of sales persons, and consumer rating system. A different approach was taken by San Martín and Jiménez (2011) who studied the role of gender in interpreting online trust signals in Spanish customers. 


\subsection{Social Factors}

The third category, identified as social factors, contains studies of the socio-cultural factors impacting online trust development: word-ofmouth, social presence, culture, trust recovery, and green trust.

- Word-of-mouth: The role of communication between customers about a company's ability, benevolence, and integrity, as well as its product is in the center of studies in this sub-category (Awad \& Ragowsky, 2008; Lee, Park, \& Han, 2011).

- Social Presence: As online shopping is viewed as impersonal, automated, and lacking human touch (Beldad et al., 2010), researchers continue to explore the impact of the virtual environment on the customers' perceptions of "human warmth and sociability" (Hassainen \& Head, 2007, p. 690). Web elements that create those perceptions - pictures of people, social networks, blogs are the main objects of study in this sub-category.

- Culture: Despite the different nuances in numerous definitions of culture there is consensus among researchers that culture is shared among people, is taught from generation to generation, and affects people's view of the world, thinking, and behavior (G. Hofstede, G.J. Hofstede, \& Minkov, 2010; Hall, 1976; Trompenaars, 1994). Culture expresses shared values that are reflected in symbols, myths, and languages (Smircich, 1983). As trust is a social phenomenon, researchers investigate how cultural backgrounds of online shoppers might impact online trust development as the culture of shoppers might not be the same as the cultural background of the retailers (Bente et al., 2014; Casaló et al., 2011). When people from two identical cultures interact, the trust building process should be "relatively straightforward" (Saunders, Skinner, \& Lewicki, 2010, p. 19). However, when people from different cultures interact, they use their value systems to analyze cues or trust symbols displayed by others. As a result, there might be misunderstanding and misinterpretation of intentions (Dietz, Gillespie, \& Chao, 2010) which could lead to abandoning the website.

- Trust recovery: In situations when unsatisfied consumers complain about their online shopping experiences, e-retailers handle those complaints differently. Failure to address customers' complaints lead to reduced trust while satisfactory approaches to solving customers' complaints can enhance trust (Pizzutti \& Fernandes, 2010).

- Green trust: A new research area was found among social factors - the "green" consumer movement. Chen and Chang (2013) offered a new managerial framework that combines the phenomenon of green marketing and relationship marketing into green trust. Green trust was defined as "a willingness to depend on a product, service, or brand based on the belief or expectation resulting from its credibility, benevolence, and ability about its environmental performance" (Chen \& Chang, 2013, p.72).

\section{Discussion}

The purpose of this literature review was to identify the main trends in academic research of online trust in e-commerce during the 20042014 period and not to evaluate or judge the state of this research. Although 138 publications were selected that met the initial inclusion criteria, only 54 papers were included in this review. These studies showed a fair diversity of topics, but the results of the content analysis revealed the concentration of studies in three main areas: trust models, technological and social factors impacting online trust.

The scope of trust models extends from studying antecedents or determinants of online trust (Gregori et al., 2014; Hwang, 2009; Peštek, Resić, \& Nožica, 2011) to researching the impact of online trust on the consumer buying behavior (Chau et al., 2007; Chiu et al., 2009), from investigating specifics of initial online trust (Chen \& Barnes, 2007; $\mathrm{Wu}, \mathrm{Hu}, \& \mathrm{Wu}, 2010)$ to studying a possibility of transfer of traditional trust in "brick" retailers to "click" retailers (Bock et al., 2012; Kuan \& Bock, 2007) to comparing antecedents of trust and distrust as two coexisting constructs (Chang \& Fang, 2013). The fact that this topic is the top research area shows the on-going interest to studying factors impacting online trust and continuous attempts to create a framework for online trust (Beldad et al., 2010).

Due to the higher number of uncertain aspects in e-commerce, development of trust is significantly more important, but also more difficult, in the online environment than in a face-to-face situation. Online buyers are separated from online retailers in time and place (Pavlou, Liang, \& Xue, 2007; Riegelsberger et al., 2005), and shoppers can not touch, smell, taste or try on tangible products (Chen \& Dibb, 2010). Due to these specifics of online exchanges, there is a higher level of opportunism: an online vendor can take the payment but either delivers a wrong product or does not deliver at all; there is a possibility of a retailer to delay a product delivery or not to exchange a faulty product (Peštek, Resić, \& Nožica, 2011). Negative consequences of online transactions that might go wrong are greater than the possible positive outcome (Lee \& Turban, 2001). Hence the trend in the online trust studies is to explore antecedents of online trust, initial trust, and trust development. If a consumer does not develop initial trust in an e-retailer from the initial visit, then there is a little chance of a consumer returning to that website (Wang, Guo, Niu, \& Li, 2011).

When observing the dominant trends in online trust research, two approaches stand out - studying online trust from a technological perspective or the social one. The technological perspective reviews online tools and the Web capabilities to complete a transaction. The social approach focuses on the impact of the online community and personal attributes of an online buyer. It appears, however, that studies combine both: it is difficult to consider online word-of-mouth, for example, as an online trust antecedent if an e-vendor does not offer a blog or a review system for customers. If a website does not have this feature, does it mean that customers do not develop online trust toward that vendor? Or, on the other hand, if technologically, a website is designed with the use of all the latest interactive tools $3 \mathrm{D}$ images, online chat with a customer service representative, high 
customization of a website, and other tools - does it help a customer develop online trust without considering that customer's social environment and personal characteristics?

As Table 2 shows, the top four research areas are determinants of trust, website design, trust signals, and initial trust. The least explored two topics are green trust and trust recovery, as only one article was found in each of those sub-categories. The only article in the area of green trust found for this literature review suggests that companies which embraced environmental protection as a part of their social responsibility and business strategy should integrate concepts of green marketing into all marketing activities (Chen \& Chang, 2013). Green marketing refers to all activities that generate and facilitate exchanges to satisfy consumers' needs with minimal impact on the natural environment (Polonsky, 1994). It is argued that companies need to reveal more information about their product and its impact on the natural environment to allow customers compare green products to traditional ones. This comparison helps to reduce perceived risks and concerns about the quality of a green product. Chen and Chang (2013) introduced the new constructs of "green perceived quality" and "green perceived risk" and empirically tested the relationships between green perceived quality, green perceived risk, green satisfaction, and green trust.

Process of trust repair after a company's failure to deliver a product was studied previously both in the situation of a traditional, face-toface environment (Dietz \& Gillespie 2012) and in online situations, especially with regard to government websites (Beldad et al., 2012; Schaupp, Carter, \& McBride, 2010). However, research of online trust recovery in the context of e-commerce seems to be understudied. A quick search in the Google Scholar using the key phrase "online trust recovery" did not return any results, a follow-up search with the phrase "online trust repair" did not show any articles within that database.

\section{Contribution and Practical Implications}

The most important contribution of this review is that it identifies trends in trust research in the area of e-commerce in the Web 2.0 environment in 2004-2014. Analyzing those trends helps to identify understudied areas and suggest some future areas for online trust research in Web 3.0.

As our literature review shows, one of the new areas of studies deals with green trust. Although this type of trust seems to reflect consumers' trust in particular characteristics of some products rather than overall online trust, an interesting study could be to investigate if indeed green trust could be treated as a different type of trust in a specific context. It would emphasize trust toward green marketing in both traditional and online environment, thus adding to existing trust classifications.

The area of trust recovery in the commercial online environment could and should be explored in more details. Establishing longterm customer relationships based on trust and commitment is a successful business strategy (Morgan \& Hunt, 1994). Unfortunately, not all e-vendors implement this strategy flawlessly, and issues of failing to deliver as promised and online fraud are still abound. For example, the fraud rate in online transactions in China alone was noted to be between $9 \%$ and $47 \%$ during seven months (October 17, 2008, and May 17, 2009) (Zhang et al., 2013).

This literature review also shows that there is another area that is not studied in depth as it was missing in the topics presented in Table 2. Since an e-vendor presents a product virtually, it is easy for a company to exaggerate that product's value and qualities. An area that seems to be understudied is online ethics and trust. Cheng, Yang, Chen, and Wu (2011) defined ethics in e-commerce (EC) as "as a consumer's perception about the practice of the EC website in its handling of consumers in a confidential, fair, honest and sincere manner in the transaction process"(p. 4503). Overall, the studies of ethics in e-commerce identified the top ethical issues as fraud, intellectual property, privacy and informed consent, protection of children, security of information, product warranty, plagiarism, and trust (Cheng et al., 2011; Roman, 2007; Kracher \& Corritore, 2004). However, not a single article on ethics and trust was found among the studies selected for this literature review. Hence, there is a lack of studies investigating a direct impact of e-vendors' ethical conduct on online consumer trust, which constitutes a research gap in online trust research.

These three areas (green trust, trust recovery, and the role of ethics in developing online trust) rate high on the online trust research agenda. Studying these in detail will help not only to extend our knowledge of various dimensions of online trust but contribute to practical solutions in some key problems in online trust development.

\section{Limitations and Future Research}

This literature review has its limitations:

First, it is not exhaustive because the number of online trust studies in the commercial environment meeting the strict criteria of our selection process was not very numerous in the databases used for this review. A similar search in Google Scholar (a combination of "online trust" AND "e-commerce" for the 2004-2014 period run on November 3, 2014, for example, returned the total number of 4,340 articles while EBSCO showed 29 articles when searched with these keywords. This variation in number (from 29 to 4,340) of papers available online could be explained by the differences in algorithm approaches used by the databases and search engines in finding articles that match key phrases. It should be noted that some papers were omitted unintentionally as the results of the Web of Science served as the foundation for this review. Any literature review is biased when it comes to the selection criteria used to identify papers for a review. Narrowing our choice of literature offers a better focus on the topic of discussion but makes generalization difficult.

Second, there was a significant challenge to clearly and distinctly identify the major area of research and some of the articles could have been grouped in several categories. 
Despite these limitations, this paper is the first systematic attempt to offer a review of research trends in the area of online consumer trust. It presents initial findings that lead to identifying areas for future research. This literature review covered studies evolving around the Web 2.0. The term "Web 2.0" (read-write) refers to the second generation of the Internet that takes advantage of the network nature of the Web where participants can contribute to the online content. Unlike Web 1.0 (the Web of documents) where Web administrators published files for public to read online (Hiremath \& Kenchakkanavar, 2016), Web 2.0 (the Web of people) is a set of applications that help to create, validate, manage, share and consume information (Aghaei, Nematbakhsh, \& Farsani, 2012). The extension of the Web 2.0 is Web 3.0 (Antunes, Freire, \& Costa, 2016), which is referred to as the semantic web or the web of data. The purpose of the semantic web is to allow seamless integration of different sources in various formats into one application. It means that the vast volume of data is read and processed by the system rather than people. It also changes the focus from "human in the loop to humanity in the loop" (Hendler \& Berners-Lee, 2010, p. 160). Trust as a social concept is a major part of this humanity in the loop as noted by both researchers and practitioners (Artz \& Gill, 2007; Hendler \& Berners-Lee, 2010).

It would be of interest to review online trust research trends in the era of the Web 3.0 to see if the main trends remain the same or change, and if they change - what direction and why. Since the technological progress has not stopped and some researchers have already introduced Web 4.0 as "symbiotic Web" (Aghaei et al., 2012, p. 8), this type of review could provide an academic foundation for trust research of Web 4.0.

Another area of future research could and should be mobile and social commerce as new subcategories of e-commerce. Recent technological advancements led to the development of mobile electronic devices (such as smartphones and tablets). Online shoppers started using these devices for purchases thus creating a new phenomenon of mobile commerce. Mobile commerce or m-commerce is defined as a subset of e-commerce (Ngai \& Gunasekaran, 2007) which uses wireless, radio-type signals to conduct business transactions on the Web (Siau \& Shen, 2003; Yeh \& Li, 2009).

The popularity of social networks and users' increased involvement in social media have changed online consumer purchasing behavior and led to a new type of the business model known as social commerce or s-commerce (Liang \& Turban, 2012). This new type of e-commerce combines social networking and shopping into one experience (Hsiao et al., 2010). Social commerce or s-commerce was defined as 'a new business model of e-commerce driven by social media (e.g., SNSs) that facilitates the purchasing and selling of various products and services' (Kim \& Park, 2013, p. 319). Since by definition, social commerce is based on the product reviews created by customers, trust is more important here than in e-commerce due to a higher level of interactivity where trust in participants of a social network becomes crucial (Kim \& Park, 2013). Once consumers trust product recommendations, they are more likely to buy that product (Hsiao et al., 2010).

\section{Conclusion}

Online trust has been a focus of research in various academic disciplines. This paper reviews only studies on consumer online trust in e-commerce conducted and published in 2004-2014. This period was selected as it marks the start and the tenth anniversary of the Web 2.0 technological developments that made the Internet truly interactive (O’Reilly, 2007). One hundred and thirty-eight articles were reviewed in preparation of this paper. Fifty-four papers were selected for analysis: five of them reviewed literature, six contributed to the theory development, and forty-three articles reported empirical research in the area of online trust in the commercial environment. An interpretive approach to research synthesis was used when the content of papers selected for the literature review was analyzed, the emerging themes coded and described (Rousseau et al., 2008; Tranfield et al., 2003). As the result of the analysis, this paper highlights three major research themes (trust models, technological and social factors impacting online trust) and explores topics in each major theme found in direct studies of online consumer trust.

This paper enhances the scientific community's understanding of the existing body of knowledge about online trust. As it is based on the concept-centric approach (Levy \& Ellis, 2006; Webster \& Watson, 2002), it points out not only the major trends in research but also some understudied areas that might help other researchers to expand our knowledge of online trust.

\section{References}

Aghaei, S., Nematbakhsh, M.A., \& Farsani, H. K. (2012). Evolution of the World Wide Web: From WEB 1.0 TO WEB 4.0. International Journal of Web \& Semantic Technology, 3(1), 1-10.

Aiken, D. \& Boush, D. (2006). Trustmarks, Objective-Source Ratings, and Implied Investments in Advertising: Investigating Online Trust and the Context-Specific Nature of Internet Signals. Journal of the Academy of Marketing Science, 34(3), 308-323.

Antunes, F., M. Freire, M., \& Costa, J.P. (2016). Semantic web and decision support systems. Journal of Decision Systems, 25(1), 79-93.

Artz, D. \& Gil, Y. (2007). A survey of trust in computer science and the semantic web. Web Semantics: Science, Services and Agents on the World Wide Web, 5(2), 58-71.

Awad, N. F., \& Ragowsky, A. (2008). Establishing trust in electronic commerce through online word of mouth: An examination across genders. Journal of Management Information Systems, 24(4), 101-121.

Bachmann, R. (2010). Towards a context-sensitive approach to researching trust in inter-organizational relationships. In Mark N.K. Saunders, Denise Skinner, Graham Dietz, Nicole Gillespie and Roy J. Lewicki (eds). Organizational Trust: A Cultural Perspective, (pp. 87-106). Cambridge: Cambridge University Press. 
Bachmann, R. \& Inkpen, A. C. (2011). Understanding institutionalbased trust building processes in inter-organizational relationships. Organization Studies, 32(2), 281-301.

Barber, B. (1983). The Logic and Limits of Trust. New Brunswick, NJ: Rutgers.

Bart, Y., Shankar, V., Sultan, F., \& Urban, G.L. (2005). Are the drivers and role of online trust the same for all Web sites and consumers? A largescale exploratory empirical study. Journal of Marketing, 69(4), 133-152.

Beldad, A., de Jong, M., \& Steehouder, M. (2010). How shall I trust the faceless and the intangible? A literature review on the antecedents of online trust. Computers in Human Behavior, 26(5), 857-869.

Benbasat, I., Gefen, D. , \& Pavlou, P. (2008) Special Issue: Trust in Online Environments. Journal of Management Information Systems, 24(4), 5-11.

Bente, G., Dratsch, T., Kaspar, K., Häßler, T., Bungard, O., \& Al-Issa, A. (2014). Cultures of Trust: Effects of Avatar Faces and Reputation Scores on German and Arab Players in an Online Trust-Game. PloS one, 9(6), e98297. Retrived from: http://www.plosone.org/article/ info\%3Adoi\%2F10.1371\%2Fjournal.pone.0098297

Blau, P. M. (1974). On the Nature of Organizations. USA: Wiley.

Bock, G. W., Lee, J., Kuan, H. H., \& Kim, J. H. (2012). The progression of online trust in the multi-channel retailer context and the role of product uncertainty. Decision Support Systems, 53(1), 97-107.

Carley, K. (1993). Coding choices for textual analysis: A comparison of content analysis and map analysis, Sociological Methodology, 23, 75-126.

Casaló, L. V., Flavián, C., \& Guinalíu, M. (2011). The generation of trust in the online services and product distribution: The case of Spanish electronic commerce. Journal of Electronic Commerce Research, 12(3), 199-213.

Caudill, E. M. \& Murphy, P.E. (2000). Consumer Online Privacy: Legal and Ethical Issues, Journal of Public Policy and Marketing, 19(1), 7-19.

Chang, M.K., Cheung, W., \& Lai, V.S. (2005) Literature derived reference models for the adoption of online shopping. Information \& Management, 42(4), 543-559.

Chang, Y. S., \& Fang, S. R. (2013). Antecedents and distinctions between online trust and distrust: Predicting high-and low-risk Internet behaviors. Journal of Electronic Commerce Research, 14(2), 149-166.

Chattaraman, V., Kwon, W. S., \& Gilbert, J. E. (2012). Virtual agents in retail web sites: Benefits of simulated social interaction for older users. Computers in Human Behavior, 28(6), 2055-2066.

Chau, P. Y., Hu, P. J. H., Lee, B. L., \& Au, A. K. (2007). Examining customers' trust in online vendors and their dropout decisions: an empirical study. Electronic Commerce Research and Applications, 6(2), 171-182.
Chen, Y. H., \& Barnes, S. (2007). Initial trust and online buyer behaviour. Industrial Management \& Data Systems, 107(1), 21-36.

Chen, Y. S., \& Chang, C. H. (2013). Towards green trust: The influences of green perceived quality, green perceived risk, and green satisfaction. Management Decision, 51(1), 63-82.

Chen, J. \& Dibb, S. (2010). Consumer Trust in the Online Retail Context: Exploring the Antecedents and Consequences. Psychology \& Marketing, 27(4), 323-346.

Cheng, H-F. , Yang, M-H., Chen, K-Y. \& Wu, J.B. (2011). Ethics in electronic commerce: An exploration of its consequences. African Journal of Business Management, 5, 4500-4509.

Chiu, C. M., Chang, C. C., Cheng, H. L., \& Fang, Y. H. (2009). Determinants of customer repurchase intention in online shopping. Online information review, 33(4), 761-784.

Clarke, R. \& Pucihar, A. (2013). Electronic interaction research 19882012 through the lens of the Bled eConference. Electronic Markets, 23(4), 271-283.

Cook, K. Cheshire, C. Gerbasi, A. \& Aven, B. (2009) Assessing Trustworthiness in Providers. In K. Cook, C. Snijders, V. Buskens, and C. Cheshire (Eds.). eTrust: Forming relationships in the online world (pp. 189-214). New York: Russell Sage Foundation.

Corritore, C., Kracher, B. \& Wiedenbeck, S. (2003). Online trust: concepts, evolving themes, a model. International Journal of HumanComputer Studies, 58, 737-758. doi:10.1016/S1071-5819(03)00041-7

Culnan, M. (2000). Protecting Privacy Online: Is Self-Regulation Working? Journal of Public Policy and Marketing, 19(1), 20-26.

Cyr, D. (2014). Return visits: a review of how Web site design can engender visitor loyalty. Journal of Information Technology. 29(1), 1-26.

Davis, D. (2012, October 23). How Many Online Retailers are there Worldwide? Internet Retailer. Retrieved from http://www.internetretailer.com/ commentary/experts/how-many-online-retailers-are-there-worldwide/

Dietz, G. (2011) Going back to the source: Why do people trust each other? Journal of Trust Research, 1(2), 215-222.

Dietz, G., \& Gillespie, N. (2012). Recovery of Trust: Case Studies of Organisational Failures and Trust Repair, Vol. 5. London: Institute of Business Ethics.

Dietz, G., Gillespie, N., \& Chao, G. (2010). Unravelling the complexities of trust and culture. In M. Saunders, D. Skinner, G. Dietz, N. Gillespie, \& R. Lewicki (Eds), Organizational Trust: A Cultural Perspective (pp. 3 - 41). Cambridge: Cambridge University Press.

Edelman, B. (2011). Adverse selection in online "trust" certifications and search results. Electronic Commerce Research and Applications, 10(1), 17-25. 
Fan, M., Ming, Y.T., \& Whinston, A.B. (2005). Evaluation and design of online cooperative feedback mechanisms for reputation management. IEEE Transactions on Knowledge and Data Engineering, 17(2), 244-254.

Fang, Y. H., Chiu, C.M., \& Wang, E.T. (2011) Understanding customers' satisfaction and repurchase intentions: An integration of IS success model, trust, and justice. Internet Research, 21(4), 479-503.

Fukuyama, F. (1995) Trust: The Social Virtues and the Creation of Prosperity. New York: The Free Press.

Grabner-Kraeuter, S. \& Kaluscha, E. A. (2008). Consumer trust in electronic commerce: Conceptualization and classification of trust building measures. In T. Kautonen, \& H. Karjaluoto (Eds.), Trust and new technologies (pp. 3-22). Cheltenham: Edward Elgar.

Gray, J. H. \& Densten, I. L. (1998). Integrating quantitative and qualitative analysis using latent and manifest variables. Quality and Quantity, 32(4), 419-431.

Gregori, N., Daniele, R., \& Altinay, L. (2014). Affiliate Marketing in Tourism Determinants of Consumer Trust. Journal of Travel Research, 53(2), 196-210.

Hall, E. T. (1976). Beyond Culture. Anchor Press/Doubleday: Garden City, New York.

Hassanein, K., \& Head, M. (2007). Manipulating perceived social presence through the web interface and its impact on attitude towards online shopping. International Journal of Human-Computer Studies, 65(8), 689-708.

Hendler, J. \& Berners-Lee, T. (2010). From the Semantic Web to social machines: A research challenge for AI on the World Wide Web. Artificial Intelligence, 174(2), 156-161.

Hiremath, B. K. \& Kenchakkanavar, A. Y. (2016). An Alteration of the Web 1.0, Web 2.0 and Web 3.0: A Comparative Study. Imperial Journal of Interdisciplinary Research, 2(4), 705-710.

Hofstede, G. Hofstede, G.J. Minkov, M. (2010). Cultures and Organizations: Software of the Mind: Intercultural Cooperation and its Impor-tance for Survival ( $3^{\text {rd }}$ edition). New York: McGraw Hill.

Hsiao, K.-L. Lin, J. Wang, X.-Y. Lu, H.-P., \& Yu, H. (2010). Antecedents and consequences of trust in online product recommendations: An empirical study in social shopping. Online Information Review, 34 (6), 935-953.

Hwang, Y. (2009). The impact of uncertainty avoidance, social norms and innovativeness on trust and ease of use in electronic customer relationship management. Electronic Markets, 19(2-3), 89-98.

Jarvenpaa, S. \& Rao V. (2003). Trust in Online Consumer Exchanges: Emerging Conceptual and Theoretical Trends. In M. Shaw (Ed.) The E-Commerce and the Digital Economy, (pp. 229-246). M.E. Sharpe, Inc.

ISSN: 0718-2724. (http://jotmi.org)

Journal of Technology Management \& Innovation @ Universidad Alberto Hurtado, Facultad de Economía y Negocios.
Karimov, F. Brengman, M. Van Hove, L. (2011). The Effect of Web Site Design dimensions on Initial Trust: A Synthesis of the Empirical Literature. Journal of Electronic Commerce Research, 12(4), 272-301.

Kim, D.J., Ferrin, D. L., \& Rao, H.R.(2009). Trust and satisfaction, two stepping stones for successful e-commerce relationships: A longitudinal exploration. Information Systems Research, 20(2), 237-257.

Kim, S. \& Park, H. (2013). Effects of various characteristics of social commerce (s-commerce) on consumers' trust and trust performance. International Journal of Information Management, 33, 318-332.

Kracher, B. \& Corritore, C. (2004). Is there a special e-commerce ethics? Business Ethics Quarterly, 14(1), 71-94.

Kuan, H. H., \& Bock, G. W. (2007). Trust transference in brick and click retailers: An investigation of the before-online-visit phase. Information \& Management, 44(2), 175-187.

Lee, J., Park, D. H., \& Han, I. (2011). The different effects of online consumer reviews on consumers' purchase intentions depending on trust in online shopping malls: an advertising perspective. Internet research, 21(2), 187-206.

Lee, K.C., Kang, I. \& McKnight, D. H. (2007). Transfer from offline trust to key online perceptions: an empirical study. IEEE Transactions on Engineering Management, 54(4), 729-741.

Lee, M. \& Turban, E. (2001). A Trust Model for Consumer Internet Shopping. International Journal of Electronic Commerce, 6(1), 75-91.

Levy, Y., \& Ellis, T. J. (2006). A systems approach to conduct an effective literature review in support of information systems research. Informing Science: International Journal of an Emerging Transdiscipline, 9(1), 181-212.

Li, H. Jiang, J., \& Wu, M. (2014). The effects of trust assurances on consumers' initial online trust: A two-stage decision-making process perspective. International Journal of Information Management, 34(3), 395-405.

Liang, T.-P. \& Turban, E. (2012) Introduction to the Special Issue Social Commerce: A Research Framework for Social Commerce. International Journal of Electronic Commerce, 16(2), 5-13.

Luhmann, N. (1979). Trust and Power. Chichester: John Wiley \& Sons.

Makame, W. H., Kang, J., \& Park, S. (2014). Factors influencing elec-tronic commerce adoption in developing countries: The case of Tan-zania. South African Journal of Business Management, 45(2), 83-96.

Markoff, J. (2006, November) Entrepreneurs See a Web Guiding by Common Sense. New York Times. [Online] Retrieved from: http://www.nytimes.com/2006/11/12/business/12web.html?_r=0

Mayer, R. C. Davis, J. H., \& Schoorman, F.D. (1995). An Integrati-ve Model of Organizational Trust. Academy of Management Review, 20(3), 709-734. 
Mollering, G. (2006). Trust: Reason, Routine, Reflexivity. Oxford: Elsevier.

Morgan, R. Hunt, S. (1994) The Commitment-Trust Theory of Relationship Marketing. Journal of Marketing, 58(3), 20-38.

Muhammad, M. R., \& Muhammad, M. (2013). Building Trust in ECommerce: A Proposed Shariah Compliant Model, The Journal of Internet Banking and Commerce, 18(3), 1-13.

Nations, D. (2016, May) What Is Web 3.0 and Is It Here Yet? Lifewire. [Online]. Retrieved from https://www.lifewire.com/what-isweb-3-0-3486623

Ngai, E.W.T. \& Gunasekaran, A. (2007). A review for mobile commerce research and applications. Decision Support Systems, 43(1), 3-15.

Ngai, E. W. T. \& Wat F. K. T. (2002). A literature review and classification of electronic commerce research, Information Management, 39, 415-429.

O'Brien, D. \& Torres, A.M. (2012). Social networking and online privacy: Facebook users' perceptions. Irish Journal of Management, 31(2), 63-97.

O'Reilly, T. (2007). What is Web 2.0: Design patterns and business models for the next generation of software. Communications a nd Strategies, 65(1), 17-37.

Okoli, C. \& Schabram, K. (2010). A Guide to Conducting a Systematic Literature Review of Information Systems Research. Sprouts: Working Papers on Information Systems, 10(26). Retrieved from http://sprouts.aisnet.org/10-26

Pavlou, P. A., Liang, H., \& Xue, Y. (2007). Understanding and mitigating uncertainty in online exchange relationships: a principal-agent perspective. MIS Quarterly, 31(1), 105-136.

Peštek, A., Resić, E., \& Nožica, M. (2011). Model of trust in E-Transactions. Ekonomska istraživanja, 24(3), 131-146.

Pettit, P. (1995). The Cunning of Trust. Philosophy and Public Affairs, 24(3), 202-225.

Pizzutti, C., \& Fernandes, D. (2010). Effect of recovery efforts on con-sumer trust and loyalty in e-tail: a contingency model. International Journal of Electronic Commerce, 14(4), 127-160.

Polonsky, M. J. (1994). An introduction to green marketing. Electro-nic Green Journal, 1(2). Retrieved from http:// escholarship.org/uc/item/49n325b7

Riegelsberger, J., Sasse, M. A., \& McCarthy, J. D. (2005). The mecha-nics of trust: A framework for research and design. International Jour-nal of Human-Computer Studies, 62(3), 381-422.

Roman, S. (2007). Ethics of Online Retailing: A Scale Development and Validation from the Consumers' Perspective. Journal of Business Ethics, 72(2), 131-148.
Rousseau, D. M., Manning, J., \& Denyer, D. (2008). Evidence in Management and Organizational Science: Assembling the Field's Full Weight of Scientific Knowledge Through Syntheses. SSRN eLibrary. Retrieved from http://papers.ssrn.com/sol3/papers.cfm?abstract_id=1309606

Rousseau, D., Sitkin, S., Burt, R., \& Camerer, C. (1998). Not so different after all: A cross-discipline view of trust. Academy of Management Review, 23(3), 393-404.

Roy, S. \& Ghose, S. (2006). Internet adoption as a two-stage transition-Converting internet non-users to internet users and to online buyers. International Journal of Market Research, 48(3), 321-349.

San Martín, S., \& Jiménez, N. H. (2011). Online buying perceptions in Spain: can gender make a difference? Electronic Markets, 21(4), 267-281.

Saunders, M., Skinner, D., \& Lewicki, R. (2010). Emerging themes, implications for practice, and directions for research. In M. Saunders, D. Skinner, G. Dietz, N. Gillespie, \& R. Lewicki (Eds, Organizational Trust: A Cultural Perspective (pp. 407-423). Cambridge: Cambridge University Press.

Schaupp, L. C., Carter, L., \& McBride, M. E. (2010). E-file adoption: A study of US taxpayers' intentions. Computers in Human Behavior, 26(4), 636-644.

Shankar, V., Urban, G. L., \& Sultan, F. (2002). Online trust: A stakeholder perspective, concepts, implications, and future directions. Journal of Strategic Information Systems, 11(3), 325-344.

Siau, K. \& Shen, Z. (2003). Building Customer Trust in Mobile Commerce. Communications of the ACM, 46(4), 91-94.

Smircich, L. (1983). Concepts of Culture and Organizational Analysis. Administrative Science Quarterly, 28(3), 339-358.

Tranfield, D., Denyer, D. \& Smart, P. (2003). Toward a methodology for developing evidence-informed management knowledge by means of systematic review. British Journal of Management, 14, 207-222.

Trompenaars, F. (1994) Riding the Waves of Culture: Understanding Diversity in Global Business. Burr Ridge, IL: Irwin.

Urban, G. Amyx, C. Lorenzon, A. (2009). Online Trust: State of the Art, New Frontiers, and Research Potential. Journal of Interactive Marketing, 23(2), 179-190.

Wang, C.-C. \& Chen, C.-C. (2010). Electronic Commerce Research in Latest Decade: A Literature Review. International Journal of Electronic Commerce Studies, 1(1), 1-14.

Wang, Y. D. \& Emurian, H. (2005). An Overview of Online Trust: Concepts, Elements, and Implications. Computers in Human Behavior, 21, 105-125.

Wang, B., Guo, X., Niu, H., \& Li, H. (2011, August). A Review and Prospects of Initial Trust in E-Commerce. In Management and Service Science (MASS), 2011 International Conference on (pp. 1-4). IEEE. 
Wareham, J., Zheng, J. G., \& Straub, D. (2005). Critical themes in electronic commerce research: a meta-analysis. Journal of Information Technology, 20(1), 1-19.

Webster, J., \& Watson, R. T. (2002). Analyzing the past to prepare for the future: Writing a literature review. Management Information Sys-tems Quarterly, 26(2), xiii - xxiii.

Wheelen, T. L., Hunger, J.D., Hoffman, A.N., \& Bamford, C.E. (2015). Concepts in Strategic Management and Business Policy: Globalization, In-novation, and Sustainability, $14^{\text {th }}$ ed., Upper Saddle River, NJ: Pearson.

Wirtz, B.W., Schilke, O., \&Ullrich, S. (2010). Strategic development of business models: implications of the Web 2.0 for creating value on the Internet. Long Range Planning, 43(2), 272-290.
Wu, G., Hu, X., \& Wu, Y. (2010). Effects of perceived interactivity, perceived web assurance and disposition to trust on initial online trust. Journal of Computer-Mediated Communication, 16(1), 1-26.

Yaobin, L. \&Tao, Z. (2007). A research of consumers' initial trust in online stores in China. Journal of Research and Practice in Information Technology, 39(3), 167-180.

Yeh, Y. \& Li, Y-M. (2009). Building trust in m-commerce: contribution from quality and satisfaction. Online Information Review, 33(6), 1066-1086.

Zhang, Y., Bian, J., \& Zhu, W. (2013). Trust fraud: A crucial challenge for China's e-commerce market. Electronic Commerce Research and Applications, 12(5), 299-308. 